Editorial

\title{
Social Media and Medical Journals: A Promising Relationship?
}

\section{Medios sociales y periódicos médicos: ¿una relación prometedora?}

\author{
Maria José Ribal Caparros ${ }^{1}$ \\ 1 Presidenta Societat Catalana d'Urologia; L’Hospital Clínic de \\ Barcelona, Barcelona, Spain
}

Urol Colomb 2018;27:201-202.

Have you ever heard the question: "what is your impact factor?" Impact factor (IF) has become an important metric to obtain grants, to promote your own career, to justify the presence of the best speakers at meetings, as well as a measure of "professional value." It is the impact that publishing research has in our own academic life. However, we should not forget that the IF was not created to rank an individual work or paper, and for sure it was not created to measure the quality of the authors.

The IF was founded in 1955 as a tool to supposedly measure the quality of journals. The IF is calculated by various companies; one of the best known is the scientific division of Thomson Reuters, which publishes its IF calculation every June in its Journal Citation Reports. The calculation takes into account the number of viable items that a journal publishes over a 2-year period and how many citations these papers received in the following year. However, the IF is an average calculation, so it has been estimated that $20 \%$ of the articles account for $80 \%$ of the citations. Therefore, the IF can be modified by a few highly cited articles or by publishing those types of articles as review articles usually more cited. ${ }^{1}$

Currently, the IF is under debate as a fair or objective measure, and there is a trend to reconsider its absolute value. Some journals have started to cover a broader range of metrics. ${ }^{2}$ The San Francisco Declaration on Research Assessment (DORA) has recommended publishers to offer a wider range of performance measures to assess and evaluate the academic output. $^{3}$

Social media (SoMe) has emerged as a new way of communication, and its several platforms, such as Twitter and Facebook, are commonly used nowadays to spread and discuss research. The role of these platforms in the academic field is becoming more and more evident, and it has been suggested that they could play a major role in the purpose of improving the assessment of academic works. The diffusion of scientific production is changing lately. It is no longer done only through bibliographic databases or editorial portals; now, it is fundamental to promote it both in general (Face- book and Twitter) and in scientific (Academia.edu, ResearchGate or Mendeley) social networks.

Alternative metrics (altmetrics) represents a new way of measuring the impact of scientific research in relation to the diffusion of science that is increasingly done both in general and in specific social networks. It is a very recent concept, which is based on new indicators that try to quantify the presence of the academic activity in the social network. They do not intend to substitute, but to complement, the traditional methodology based on the quotation count, such as the IF.

These metrics were created to reflect the influence of scientific works within the new digital, social and information contexts. They include, for example, how many times an item has been seen in a web space downloaded, referenced in blogs and in social media such as Facebook and Twitter, marked as favorite, or saved among the references of a bibliography manager, such as Mendeley.

There is a growing number of journals, databases, catalogues and repositories that include information about how many altmetrics citations the articles have received, in addition to traditional citations. ${ }^{3}$

These new concepts are changing the way medical journals face the new reality regarding SoME. As well as scientific meetings, medical journals increasingly use social media to spread their messages, to increase their audiences, and to promote scientific discussion.

In the urological field, journals are also moving in the direction of SoME. Most of the very well-known urological journals include references on their websites to SoMe platforms, develop blogs for discussion, include altmetrics, spread their contents through twitter accounts, promote visual abstracts to summarize the messages conveyed by the papers, etc. Moreover, 5 of the top 10 IF ranked journals in Urology have created the new role of social media editors and are active on the Twitter platform. ${ }^{4}$ - Table 1 describes the Twitter accounts and the number of followers for those journals ranked as having a high IF in medicine, as well as the more influential journals in the urology field.
Address for correspondence Maria José Ribal Caparros, MD, PhD, Hospital Clínica de Barcelona, Carrer de Villarroel, 170, 08036, Barcelona, Spain (e-mail: MariaJRibal@scu.org.co).
DOI https://doi.org/

10.1055/s-0038-1673668.

ISSN 0120-789X.

eISSN 2027-0119.
Copyright (c) 2018, Sociedad Colombiana License terms de Urología. Publicado por Thieme Revinter Publicações Ltda., Rio de Janeiro, Brazil. Todos los derechos reservados. 
Table 1 Twitter accounts and followers of top medical journals on the general and urological fields

\begin{tabular}{|l|l|l|l|l|}
\hline Journal & Twitter account & Followers & Tweets & IF \\
\hline Nature & @nature & $1,455,506$ & 7,795 & 40.137 \\
\hline Science & @sciencemagazine & $1,165,690$ & 19,228 & 37.205 \\
\hline New England Journal of Medicine & @NEJM & 513,581 & 15,841 & 72.406 \\
\hline The Lancet & @TheLancet & 322,357 & 10,113 & 47.831 \\
\hline JAMA & @JAMA_current & 254,961 & 25,279 & 44.405 \\
\hline Journal of Urology & @JUrology & 18,533 & 4,502 & 5.157 \\
\hline European Urology & @EUPlatinium & 16,596 & 5,579 & 16.265 \\
\hline Journal of Clinical Oncology & @JCO_ASCO & 11,881 & 1,880 & 24.008 \\
\hline BJU International & @BJUljournal & 11,363 & 4,413 & 4.438 \\
\hline Nature Reviews Urology & @NatRevUrol & 8,237 & 4,687 & 7.735 \\
\hline Actas Urológicas Españolas & @actasurologicas & 1,765 & 3,500 & 1.18 \\
\hline World Journal of Urology & @wjurol & 617 & 315 & 2.743 \\
\hline Scandinavian Journal of Urology & @ScanjourUrol & 362 & 137 & 1.513 \\
\hline
\end{tabular}

Abbreviation: IF, impact factor.

Engagement on SoMe can provide substantial benefits for medical journals, such as self-promotion, improvement of metrics, increase of awareness, and improvement of the peer-review process. However, there are still many challenges that should be addressed in this growing career of medical journals in SoMe. For example, there is a risk of spreading only superficial knowledge and lost in way critical information to be correctly interpreted. On the other hand, since it is a very novel scenario, we still do not know what the best practices are and how to detect unfair uses. And, finally, it still is not clear how to measure effectively the real outcomes of the dissemination of papers on SoMe. ${ }^{5}$

On the $21^{\text {st }}$ century, SoMe is influencing the way human beings communicate. The academic field cannot turn its back to it, and new ways of sharing research should be explored. Medical journals and their editors are facing an open world and they should improve the way to spread research not only for the sake of improving research itself, but also with the aim of improving awareness, implantation and patients care. Social media and medical journals are starting and unbelievable relationship with probably a brilliant future. Let's see what happens.

\section{References}

1 Smart P. Is the impact factor the only game in town? Ann R Coll Surg Engl 2015;97(06):405-408

2 Callaway E. Beat it, impact factor! Publishing elite turns against controversial metric. Nature 2016;535(7611):210-211

3 Chavda J, Patel A. Measuring research impact: bibliometrics, social media, altmetrics, and the BJGP. Br J Gen Pract 2016;66 (642):e59-e61

4 Calopedos RJS, Garcia C, Rashid P, Murphy DG, Lawrentschuk N, Woo HH. Citation indices for social media articles in urology. BJU Int 2017;119(Suppl (Suppl 5):47-52

5 Trueger NS. Medical Journals in the Age of Ubiquitous Social Media. J Am Coll Radiol 2018;15(1 Pt B):173-176 